\title{
Diagnostic accuracy of Schistosoma immunochromatographic lgG/lgM rapid test in the detection of schistosomiasis in Zambia
}

\author{
Jolezya Mudenda ${ }^{*}$, Benson M. Hamooya ${ }^{2}$, Shadreck Tembo ${ }^{1}$, Hikabasa Halwindi ${ }^{3}$, Joyce Siwila ${ }^{4}$ and \\ Masauso Moses Phiri ${ }^{1}$
}

\begin{abstract}
Background: Schistosomiasis or bilharzia is one of the neglected tropical diseases affecting over 230 million people globally. In Zambia, the infection poses as one of the major public health burdens among parasitic infections. The diagnosis of schistosomiasis in endemic countries is still a challenge. The aim of this study was to evaluate the diagnostic performance of the Schistosoma immunochromatographic (ICT) IgG-IgM rapid diagnostic test in the detection of schistosome infections from Schistosoma haematobium and mansoni in Siavonga district in Zambia.
\end{abstract}

Results: The diagnostic performance of Schistosoma ICT IgG-IgM test was evaluated using 430 of the 440 participants' samples which had complete data. The prevalence of $S$. haematobium and S. mansoni was $4.4 \%$ and $6 \%$, respectively, while seroprevalence was $71.4 \%$. The sensitivity and specificity of the Schistosoma ICT Ig G-IgM test was found to be $100 \%$ and $32.2 \%$, respectively. The associated positive predictive value was $13.8 \%$ and $100 \%$ for negative predictive value. Diagnostic accuracy [area under the curve (AUC)] was 0.57 [95\% confidence interval (Cl) 0.52, 0.62].

Conclusions: The Schistosoma ICT IgG-IgM proved to have remarkably high sensitivity with a fairly good specificity and diagnostic accuracy for the detection of both urinary and intestinal schistosomiasis. We therefore recommend the test as it is ideal for screening in the light of current focus of disease elimination in endemic countries.

Keywords: Schistosomiasis, Parasitic infections, ICT lgG-IgM test, Schistosoma haematobium, Schistosoma mansoni, Diagnostic accuracy

\section{Background}

Schistosomiasis, also known as bilharzia, is a chronic infectious disease affecting over 230 million people globally (Colley et al., 2014). In Zambia, it is one of the major public health burdens among the neglected tropical diseases (NTDs) with a prevalence of $>16 \%$, second only to malaria among the parasitic infections $(\mathrm{MOH}, 2017$; WHO, 2018). The two main forms in which the disease occurs are urinary and intestinal schistosomiasis. The major causative agents for intestinal schistosomiasis are

\footnotetext{
*Correspondence: jemudenda@yahoo.com

${ }^{1}$ Department of Pathology and Microbiology, School of Medicine,

Ridgeway, P.O. Box 50110, Lusaka, Zambia

Full list of author information is available at the end of the article
}

Schistosoma mansoni and S. japonicum (El-Ridi, 2013), while urinary schistosomiasis is caused by $S$. haematobium as it is the only known disease agent (Colley et al., 2014; El-Ridi, 2013; Kalinda et al., 2018; Mutengo et al., 2014).

The definitive diagnosis of schistosomiasis has traditionally been achieved by urine filtration for $S$. haematobium and Kato-Katz thick smears for S. mansoni. These methods detect active infection of schistosomiasis by visualizing schistosome eggs in either urine and/or stools under a microscope. The drawback, however, of these methods is a lack of sensitivity in detecting early infections. The scale-up of the preventative chemotherapy campaign, where the helminth egg output is likely to 
reduce, will probably worsen the reduction in sensitivity of the traditional diagnostic tools. This raises a need for sensitive tools essential for sustainable impact to eliminate schistosomiasis in endemic countries (Kalinda et al., 2018; $\mathrm{MOH}, 2017$; Ross et al., 2017; Shehata et al., 2018; WHO, 2018).

Schistosomiasis diagnosis in Zambia poses several challenges such as cost, time, infrastructure, and equipment. There is also a shortage of trained personnel to competently analyse the stool and/or urine samples (Enk et al., 2012; Lodh et al., 2013). New advances have been made in serological diagnostics of schistosomiasis that use antigen/antibody/DNA tests. However, these tools are unavailable or often fraught with many challenges in endemic regions. Although some techniques such as the polymerase chain reaction (PCR) method have proved to be the most accurate in detecting the parasite's DNA (Lodh et al., 2013) and have greater sensitivity in the diagnosis of both S. haematobium and mansoni (Enk et al., 2012; Ibironke et al., 2011), they are often are challenged by lack of and/or consistent power supply in lower- and middle-income countries (LMICs) (Lodh et al., 2013). This calls for innovative techniques that have high sensitivity and are accessible and applicable under such conditions (Lodh et al., 2013).

One such innovation is the Schistosoma Immunechromatographic (ICT) IgG-IgM rapid diagnostic test that was developed for the screening of African immigrants from schistosomiasis endemic areas to Europe (Diagnositics, 2020; LDBIO, 2017). The Schistosoma ICT $I g G-I g M$ was CE (European Conformity) marked and commercialized in January 2016. The test can detect both infections by $S$. mansoni and S. haematobium, making it suitable for African places where these two species are endemic (Halwindi et al., 2017). The Schistosoma ICT IgG/IgM has been reported to have sensitivity of $96 \%$ and negative predictive value of $97 \%$. When compared to circulating cathodic antigen (CCA) rapid test, it proved to have had superior diagnostic performances in both sensitivity and specificity (Beltrame et al., 2017). The test has, however, not been extensively evaluated in schistosomiasis endemic regions (Beltrame et al., 2017; Buonfrate et al., 2018). Therefore, the aim of this study was to evaluate the performance of Schistosoma ICT IgG-IgM rapid diagnostic test against the current gold standard diagnosis of schistosomiasis such as urine filtration for Schistosoma haematobium and Kato-Katz thick smears for $S$. mansoni for potential policy recommendations.

\section{Methods}

\section{Study design and site}

This was a cross-sectional study among individuals aged $\geq 18 \leq 50$ years. The study was conducted in December
2020 among participants living in Nabutezi, Butete, Siamatika, and Machamvwa areas in Siavonga district, areas known to be endemic for schistosomiasis infectionsboth S. haematobium and S. mansoni. In a previous study, these areas in particular recorded the highest number of people infected with both species (Halwindi et al., 2017), making them suitable study sites for the evaluation of the test kit. A total of 440 participants were enrolled in the study. During the screening process before seeking consent, participants who had received schistosomiasis treatment in the last 6 months were excluded. Sociodemographic data was collected using a questionnaire, and specimen containers were used for stool, urine, and blood samples. To mitigate the risk related to phlebotomy, only trained and certified phlebotomists collected blood samples. Appropriate aseptic procedures were instituted to minimize any risk of infections. No adverse events were reported during the drawing of blood samples for the index test. Individuals who were diagnosed with schistosomiasis based on microscopy were treated with Praziquantel at $40 \mathrm{mg} / \mathrm{kg}$ body weight.

\section{Laboratory analysis}

The stool samples were collected in a leak proof plastic container with an integrated spatula. Urine samples were collected in a wide mouth leak proof container between 10 am and $2 \mathrm{pm}$ to maximise yield as egg excretion of Schistosoma heamatobium occur in a circadian rhythm (Montresor et al., 1998).The specimen containers were clearly labelled with the participant's identification number, sex, age as well as date and time of collection. Once collected, specimens were processed with duplicate stool smears made from each stool sample and examined within $12 \mathrm{~h}$ for Schistosoma eggs with egg count expressed as eggs per gram of stool. Parasitological data was obtained using the standard Kato-Katz technique and urine filtration method as outlined by Katz et al. (1972). Diagnosis on urine was based on the detection of eggs of S. haematobium in $10 \mathrm{ml}$ of urine samples based on the filtration method described by Mott et al. (1982) for processing all urine samples. Infection intensities were expressed as number of eggs counted per $10 \mathrm{ml}$ urine. For quality assurance, the slides were analysed microscopically by two separate technicians.

Schistosoma ICT IgG-IgM cassettes were purchased from LDBIO Diagnostics (Lyon, France). They were stored and used according to manufacturer's guidelines. Venous blood was collected in a plain red top vacutainer and span in a centrifuge at $700 \times g$ for $3 \mathrm{~min}$. One drop of $20 \mu \mathrm{L}$ serum was added to the sample well of the Schistosoma ICT IgG/IgM cassette, followed by 3 drops of buffer solution. Test results were read after 20-30 min. Colour development of the control band indicated that the test 
was good, and a test band indicated if the result is positive or not.

\section{Data analysis plan}

The data collected was first entered in Research Electronic Data Capture (REDCap) and thereafter exported to Stata version 15 for analysis. Descriptive statistics (frequency, mean, median, proportions, range, interquartile range, standard deviation) were computed to understand the distribution of the data. The Chi-square test was used to determine the relationship between infections and sociodemographic variables. Sensitivity, specificity, and predictive values of the Schistosoma ICT IgG/IgM rapid diagnostic test were calculated relative to the reference methods of Kato-Katz technique and urine filtration method. The area under the curve (AUC) was deduced to determine the diagnostic accuracy of the Schistosoma ICT IgG-IgM test. To determine the statistical significance of the findings, $p<0.05$ and $95 \%$ confidence interval were used.

\section{Ethical consideration}

Ethical approval was granted by the University of Zambia Biomedical Research Ethics Committee (REF. No. 822-2020) and the National Health Research Authority granted permission to conduct the study. Information regarding the study was provided to the participants and their participation was solely on voluntary basis and all enrolled participants gave written informed consent.

\section{Results}

\section{Basic characteristics of the study population}

The study comprised 440 participants with a median age of 30 years [interquartile range (IQR) $(22,41)$ ] and 247 (56.1\%) were females. Majority of females compared with males had a higher prevalence of schistosomiasis $(56.8 \%$ vs. $43.2 \%)$. Using microscopy test, participants who were married $(n=34,77.3 \%)$ and used underground water $(n=40,90.9 \%)$ had a higher proportion of schistosomiasis (Table 1). The univariate analysis of factors associated with schistosome infection based on microscopy and Schistosoma ICT IgG-IgM test showed a comparable result $(p>0.05)$.

\section{Prevalence of schistosomiasis}

The prevalence of schistosome infections in urine $(S$. haematobium) was found to be rather low $(n=19$ [4.4\%]; 95\%CI 2.6-6.7), while that in stool (S. mansoni) was slightly higher $(n=26$ [6.0\%]; 95\%CI 3.9-8.6). The seroprevalence of Schistosomiasis based on Schistosoma ICT IgG-IgM (both S. haematobium and S. mansoni) was 314 (71.4\%); 95\%CI 66.9-75.5. The combined prevalence from urine and stool was found to be 44 (10.0\%); $95 \% \mathrm{CI}$ 7.3-13.2.

\section{Diagnostic performance of Schistosoma ICT IgG/lgM}

The diagnostic performance of Schistosoma ICT IgGIgM test was evaluated using 430 of 440 the participants' samples which had complete data (Fig. 1). Out of the 430, 42 individuals tested positive for schistosome infection using the reference microscopy schistosome tests as well as using the Schistosoma ICT IgG-IgM rapid tests. Of the 388 who tested negative using the standard reference method, 263 participants tested positive using the Schistosoma ICT IgG-IgM test. The remaining 125 participants were negative on both tests.

\section{Sensitivity, specificity, PPV and NPV for Schistosoma ICT test}

The diagnostic performance of Schistosoma ICT IgG$I g M$ was evaluated against the gold standard microscopy (Fig. 2A, B). Sensitivity and specificity of the Schistosoma ICT IgG-IgM test was found to be $100 \%$ (95\%CI 91.6$100)$ and $32.2 \%(95 \%$ CI $27.6-37.1)$, respectively (Table 2$)$. The associated positive predictive value was $13.8 \%$ (95\%CI 10.1-18.1) and 100\% (95\%CI 97.1-100) for negative predictive value. Diagnostic accuracy [area under the curve (AUC)] of Schistosoma ICT IgG-IgM was 0.57 (95\%CI 0.52, 0.62).

The sensitivity, specificity, positive and negative predictive values of Schistosoma ICT IgG-IgM test against urine filtration method for schistosome infection were 100\% (95\%CI 82.3-100), 30.2\% (95\%CI 25.8-34.9), 6.1\% (95\%CI 3.7-9.4) and 100\% (95\%CI 97.1-100), respectively. The Schistosoma ICT IgG-IgM test was compared to Kato-Katz for stool schistosome infection; the sensitivity and specificity of Schistosoma ICT IgG-IgM test were $100 \%$ (95\%CI $86.8-100)$ and 30.6\% (95\%CI 26.2-35.4), respectively. The positive predictive value was $8.4 \%$ (95\%CI 5.6-12.1), while the negative predictive value was 100\% (95\%CI 97.1-100).

\section{Discussion}

Our study found that the Schistosoma ICT IgG-IgM index test was highly sensitive but less specific in the detection of schistosomiasis. It proved sensitive in detecting both the S. haematobium and S. mansoni within one run. In addition, we observed a reduction in the combined prevalence of S. haematobium and S. mansoni from 13.9\% (Halwindi et al., 2017) to $10.0 \%$ among adults in Siavonga district. Generally, more females tested positive for schistosome infection compared to males. These findings are similar to those obtained by Andereck et al. (2014) and Mutengo et al. (2014) in studies done in western Zambia and Kenya, respectively (Andereck et al. 2014; Mutengo 
Table 1 Univariate comparison of the basic characteristics of the study participants

\begin{tabular}{|c|c|c|c|c|c|c|c|}
\hline \multirow[t]{2}{*}{ Characteristic } & \multirow[t]{2}{*}{$N$} & \multicolumn{3}{|c|}{ Microscopy test, $n(\%)$} & \multicolumn{3}{|c|}{ Schistosoma ICT IgG-IgM test, $n$ (\%) } \\
\hline & & $\begin{array}{l}\text { Schistosomiasis, } \\
n=44(10.0 \%)\end{array}$ & $\begin{array}{l}\text { No schistosomiasis, } \\
n=396(90.0 \%)\end{array}$ & $p$ value & $\begin{array}{l}\text { Schistosomiasis, } \\
n=314(71.4 \%)\end{array}$ & $\begin{array}{l}\text { No schistosomiasis, } \\
n=126(28.6 \%)\end{array}$ & $p$ value \\
\hline Age (years), m(IQR) & 440 & $31(21,42)$ & $30(22,40)$ & 0.516 & $31(22,41)$ & $28(21,40)$ & $0.204^{\mathrm{a}}$ \\
\hline Gender & & & & 0.923 & & & $0.955^{\mathrm{b}}$ \\
\hline Male & 193 & 19 (43.2) & $174(43.9)$ & & $138(44.0)$ & $55(43.7)$ & \\
\hline Female & 247 & $25(56.8)$ & $222(56.8)$ & & $176(56.0)$ & $71(56.3)$ & \\
\hline Marital status & & & & 0.564 & & & $0.852^{b}$ \\
\hline Yes & 324 & $34(77.3)$ & $290(73.2)$ & & $232(73.9)$ & $92(73.0)$ & \\
\hline No & 116 & $10(22.7)$ & $106(26.8)$ & & $82(26.1)$ & $34(27.0)$ & \\
\hline Education level & & & & 0.206 & & & $0.916^{b}$ \\
\hline No education & 108 & $15(34.1)$ & $93(23.5)$ & & $79(25.2)$ & $29(23.0)$ & \\
\hline Primary & 192 & $20(45.4)$ & $172(43.4)$ & & $134(42.7)$ & $58(46.0)$ & \\
\hline Secondary & 124 & $7(15.9)$ & $117(29.6)$ & & $89(28.3)$ & $35(27.8)$ & \\
\hline Tertiary & 16 & $2(4.6)$ & $14(3.5)$ & & $12(3.8)$ & $4(3.2)$ & \\
\hline Working & & & & 0.603 & & & $0.252^{b}$ \\
\hline Yes & 334 & $32(72.7)$ & $302(76.3)$ & & $243(77.4)$ & $91(72.2)$ & \\
\hline No & 106 & $12(27.3)$ & $94(23.7)$ & & $71(22.6)$ & $35(27.8)$ & \\
\hline Source of water & & & & 0.481 & & & $0.897^{b}$ \\
\hline River & 29 & $4(9.1)$ & $25(6.3)$ & & $21(6.7)$ & $8(6.3)$ & \\
\hline Underground & 411 & $40(90.9)$ & $371(93.7)$ & & $293(93.3)$ & $118(93.7)$ & \\
\hline Fisherman/woman & & & & 0.281 & & & $0.123^{b}$ \\
\hline Yes & 26 & $1(2.3)$ & $25(6.3)$ & & $22(7.0)$ & $4(3.7)$ & \\
\hline No & 414 & $43(97.7)$ & $371(93.7)$ & & $292(93.0)$ & $122(96.8)$ & \\
\hline $\begin{array}{l}\text { Knowledge about } \\
\text { schistosomiasis }\end{array}$ & & & & 0.374 & & & $0.401^{b}$ \\
\hline Yes & 433 & $44(100)$ & $389(98.2)$ & & $310(98.7)$ & $123(97.6)$ & \\
\hline No & 7 & 0 & $7(1.8)$ & & $4(1.3)$ & $3(2.4)$ & \\
\hline
\end{tabular}

$N$-number of complete values; $\mathrm{m}$ (IQR)-median- (interquartile range); $\mathrm{n}$ (\%)-frequency (percent)

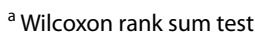

${ }^{\mathrm{b}}$ Chi-square test

et al. 2014). This observation could be due to increased water contact for domestic, recreation and agriculture activities by females. In village settings, women are the ones responsible for fetching water and most of the gardening activities hence this exposes them to increased water contact than males. None of the sociodemographic characteristics (including fishing occupation and source of drinking water) were found to be significantly associated with increased risk of schistosome infection. Deducing from the basic characteristics of the study population, it is noted that over $90 \%$ of the population had access to safe and clean underground water. This could be one of the probable reasons for reduced prevalence. It has been found that water and sanitation programs implemented as part of the efforts in the reduction in schistosomiasis infections have led to lower odds of being infected with the parasite (Esrey et al., 1991; Grimes et al., 2015). Furthermore, only a small fraction of the population (less than $10 \%$ ) is involved in fishing, an activity that enhances risk for infection despite proximity to the lake.

We evaluated a new Schistosoma immunochromatographic IgG/IgM rapid diagnostic test in reference to microscopy as the gold standard method. The overall sensitivity, specificity positive and negative predictive values of the new ICT test were $100 \%, 32.2 \%, 13.8 \%$ and $100 \%$, respectively. The urine and stool species' sensitivity, specificity, positive and negative predictive value findings were comparable. Similar findings of high sensitivity (96\%) and relatively lower specificity (62\%) were reported in a study done among African migrants in Italy (Beltrame et al., 2017). Comparable results were also obtained in a Nigerian study where the Schistosoma ICT IgG-IgM had the best sensitivity (94.9\%), fairly good specificity (63.9\%) and fairly good positive likelihood ratio when compared to urine filtration and western blot (Houmsou et al., 2021). 


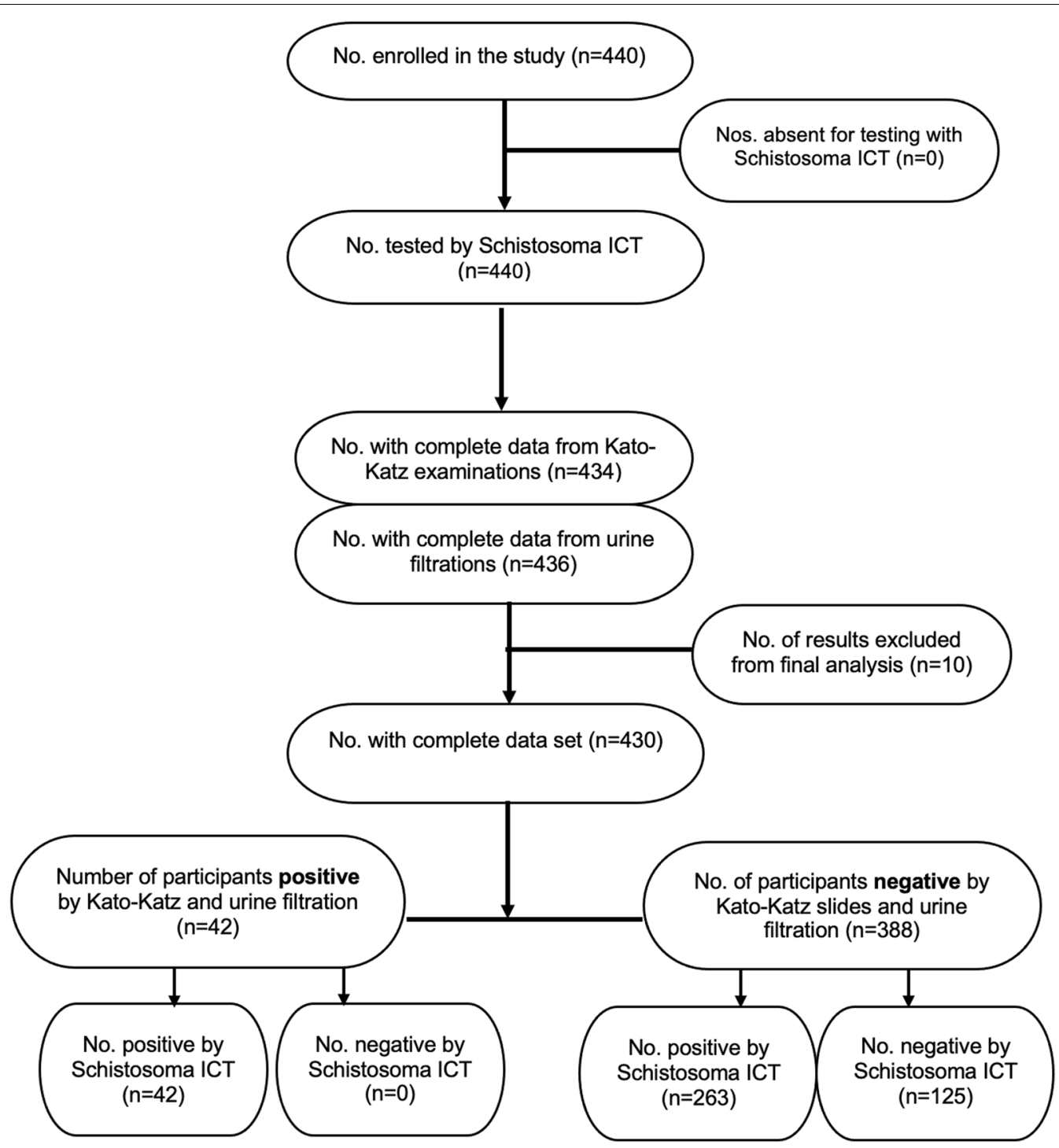

Fig. 1 Flow of participants and diagnostic performance of the Schistosoma ICT IgG-IgM

The observed high sensitivity of the Schistosoma ICT $\operatorname{Ig} G-\operatorname{Ig} M$ is a great advancement towards early diagnosis of schistosomiasis. Serological testing was found to be more efficient than quantitative polymerase chain reaction (qPCR) and Kato-Katz in detecting early infections of Schistosomiasis (Gentile et al., 2011). It has also been observed that serological IgG/IgM antibody titres increase just after infection and can be detected about 14-day post-infection (Gentile et al., 2011). The Schistosoma ICT IgG-IgM therefore would be able to offer early detection of schistosome infections and provide evidence-based treatment with Praziquantel (Houmsou et al., 2021). This ability to detect early infection may in part explain why the seroprevalence of schistosomiasis was much higher in our findings than from the gold standard method.

Our results found much lower specificity (32\%) compared to other studies $(62 \%$ and $63.9 \%)$ that evaluated the Schistosoma ICT IgG-IgM test (Beltrame et al., 2017; Buonfrate et al., 2018; Houmsou et al., 2021). The reason for this result could be attributed to our use of the parasitological method as the primary reference standard which has poor sensitivity (Beltrame et al., 2017). Other similar studies used a composite reference standard that resulted in obtaining a relatively higher specificity for the Schistosoma ICT IgG-IgM test (Beltrame et al., 2017; Houmsou et al., 2021). Generally, the Schistosoma ICT $I g G-I g M$ test was developed as a point-of-care screening 


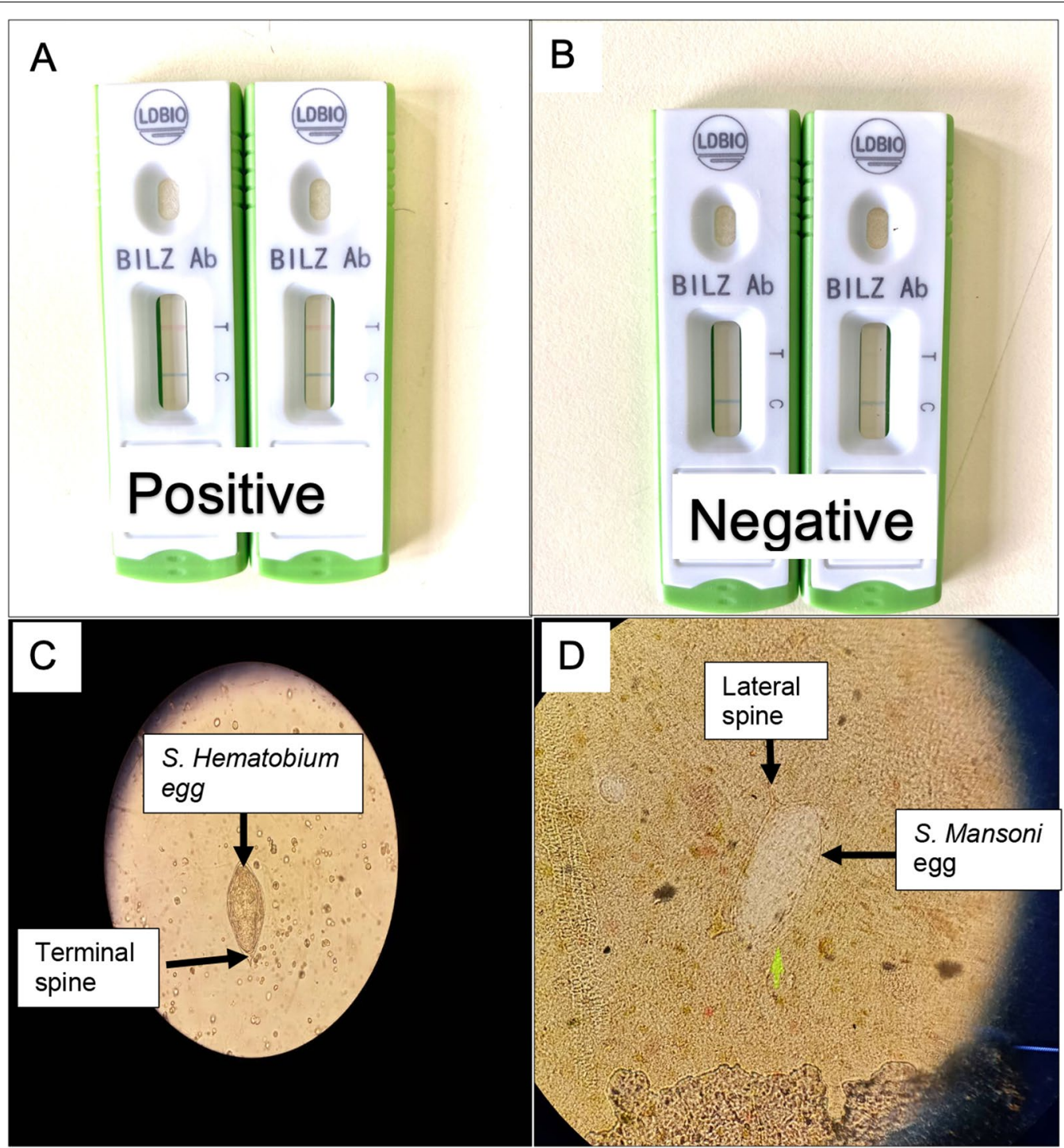

Fig. 2 Positive and negative results on the Schistosoma ICT IgG/IgM test (A, B). The negative test shows the presence of only one band-the control, whereas the positive test shows the presence of a second band. This band shows that there has been a reaction between antibodies in the sample and Schistosoma ICT IgG/IgM. Images $\mathbf{C}$ and $\mathbf{D}$ show Schistosome eggs in urine and in stool, respectively

Table 2 Overall sensitivity, specificity, PPV, NPV and diagnostic accuracy of Schistosoma ICT test

\begin{tabular}{lllr}
\hline & \multicolumn{2}{c}{ Schistosoma ICT test } & Total \\
\cline { 2 - 3 } Microscopy test (gold standard) & Positive & Negative & \\
\hline Positive & 42 & 0 & 42 \\
Negative & 263 & 125 & 388 \\
Total & 305 & 125 & 430 \\
Sensitivity $(95 \% \mathrm{Cl})$ & $100.0 \%$ & $(91.6,100.0)$ & \\
Specificity $(95 \% \mathrm{Cl})$ & $32.2 \%$ & $(27.6,37.1)$ & \\
Positive predictive value $(95 \% \mathrm{Cl})$ & $13.8 \%$ & $(10.1,18.1)$ & \\
Negative predictive value $(95 \% \mathrm{Cl})$ & $100.0 \%$ & $(97.1,100.0)$ & \\
Diagnostic accuracy $(\mathrm{AUC})(95 \% \mathrm{Cl})$ & 0.57 & $(0.52,0.62)$ & \\
\hline
\end{tabular}

test (Diagnositics, 2020) which by design, requires more adequate clinical sensitivity than specificity (Rifai et al., 2018).

The predictive value of a test describes how reliable a positive or negative result is. Predictive values are also affected by the prevalence of the disease (Rifai et al., 2018). The Schistosoma ICT IgG-IgM test had a negative predictive value of $100 \%$, meaning that for every 100 negative results, none of the tested participants is likely to have a positive schistosome infection. The observed positive predictive value of $13.8 \%$ denoted that for every 100 positive results, about 86 participants may have been false positives for schistosome infection. Therefore, a 
positive result may be due to interferences and should potentially be confirmed by an alternative method with greater specificity (Rifai et al., 2018).

Other comparative parameters make the Schistosoma ICT IgG-IgM test a relatively more favourable choice for endemic areas like Zambia. Firstly, the Schistosoma ICT $I g G-I g M$ test can detect the two most endemic species $S$. mansoni and S. haematobium infections in one run as we confirmed in our study. This is of particular importance for Zambia where these two schistosome species are coendemic in many areas. Therefore, a test with the ability to detect infection from both species could be very useful as screening tool because the same treatment is administered for both species infections (Coulibaly et al., 2013; Halwindi et al., 2017). Secondly, the Schistosoma ICT $\operatorname{IgG}-\operatorname{Ig} M$ has proved to have higher sensitivity and negative predictive value compared to the widely used pointof-care circulating cathodic antigen (POC-CCA) test (Beltrame et al., 2017; Buonfrate et al., 2018). However, the Schistosoma ICT IgG-IgM requires drawing venous blood compared to the POC-CCA which uses only urine. In a study by Buonfrate et al. (2018), use of fingerprick blood resulted in low sensitivity and specificity (Buonfrate et al., 2018). Besides being invasive, the Schistosoma ICT IgG-IgM test cassettes are expensive; hence, this may limit how wide they are adopted for use in low- and middle-income countries (Houmsou et al., 2021). It is however recommended as a suitable screening tool for schistosomiasis in endemic areas.

The strength of the study is the use of the recommended reference standard method of microscopy. We sought to directly demonstrate the presence of eggs in stool and/or urine as a confirmation for schistosome infection. Although this method is known to have poor sensitivity, especially in places of low endemicity and parasitic load, most diagnostic studies in parasitology and, in particular, schistosomiasis rely on it as the gold standard (Knopp et al., 2008). The cross-sectional study design also enabled us to capture current or recent schistosome infections, lending credence to our findings. However, one of the limitations of the study is that we did not use a composite reference standard to strengthen the evaluation of the index test and also serial collection of stool as well as urine samples was not done due to funding limitations among others.

\section{Conclusions}

The Schistosoma ICT IgG-IgM proved to have a markedly high sensitivity and a fairly good specificity for the detection of both urinary and intestinal schistosomiasis. The test demonstrated that it could be a useful tool in mapping the disease prior to conducting mass drug campaigns. In light of current shift in focus from disease control to disease elimination, the Schistosoma ICT IgG$I g M$ test is ideal as a screening tool, especially in areas of low endemicity and in adults where the egg excretion rate is greatly reduced. There is however, a need to improve the specificity of the test, reduce its cost, and enhance its ability to distinguish disease exposure from an active infection. Notwithstanding, we recommend the test for use in Zambia.

\section{Acknowledgements \\ This publication was supported by a grant from the United States Agency for International Development (USAID) and UK aid from the British people (UK aid) through the Coalition for Operational Research on Neglected Tropical Diseases (COR-NTD) and administered by the African Research Network for Neglected Tropical Diseases (ARNTD). Its contents are solely the responsibil- ity of the author(s) and do not necessarily represent the views of USAID, UK, FCDO, COR-NTD or the ARNTD.}

\section{Authors' contributions}

JM conceived/designed study/conduct/field data acquisition/analysed and interpreted results/drafting of the work. ST conduct/field data acquisition/ analysed and interpreted results/sample analysis. BMH conceived/designed study and analysed/interpreted results/revised the manuscript. HH conceived/ designed study and analysed/interpreted results/revised the manuscript. JS conceived/designed study and analysed/interpreted results/revised the manuscript. MMP conceived/secured funding/designed study/conduct/field data acquisition/analysed and interpreted results/drafting of the work. All the authors read and approved the manuscript.

\section{Funding}

Funding was provided by the African Research Network for Neglected Tropical Diseases (ARNTD) under the Small Grants Program reference SGPIII/0210/345.

Availability of data and materials

The dataset used and/or analysed during the current study is available from the corresponding author on reasonable request.

\section{Declarations}

\section{Ethics approval and consent to participate}

Ethical approval was granted by The University of Zambia Biomedical Research Ethics Committee (UNZABREC) reference number 822-2020. Further permission was sought from the National Health Research Authority (NRHA).

Consent for publication

Not applicable.

\section{Competing interests}

The authors declare that they have no competing interests.

\section{Author details}

${ }^{1}$ Department of Pathology and Microbiology, School of Medicine, Ridgeway, P.O. Box 501 10, Lusaka, Zambia. ${ }^{2}$ Department of Public Health, School of Medicine, Mulungushi University, Livingstone, Zambia. ${ }^{3}$ School of Public Health, University of Zambia, P.O. Box 50110, Lusaka, Zambia. ${ }^{4}$ Department of Clinical Studies, School of Veterinary Medicine, University of Zambia, P. O. Box 32379 , Lusaka, Zambia.

Received: 25 August 2021 Accepted: 22 January 2022

Published online: 03 February 2022

\section{References}

Andereck, J. W., Kipp, A. M., Ondiek, M., \& Vermund, S. H. (2014). Helminth prevalence among adults in rural Kenya: A stool survey for soil-transmitted helminths and schistosomiasis in Nyanza province. Transactions of the 
Royal Society of Tropical Medicine and Hygiene, 108(12), 804-809. https:// doi.org/10.1093/trstmh/tru164

Beltrame, A., Guerriero, M., Angheben, A., Gobbi, F., Requena-Mendez, A., Zammarchi, L., Formenti, F., Perandin, F., Buonfrate, D., \& Bisoffi, Z. (2017). Accuracy of parasitological and immunological tests for the screening of human schistosomiasis in immigrants and refugees from African countries: An approach with latent class analysis. PLOS Neglected Tropical Diseases, 11(6), e0005593. https://doi.org/10.1371/journal.pntd.0005593

Buonfrate, D., Rodari, P., Brunelli, D., Degani, M., Ragusa, A., Tais, S., Todeschini, M., \& Bisoffi, Z. (2018). Diagnostic study on an immunochromatographic rapid test for schistosomiasis: Comparison between use on serum and on blood spot from fingerprick. British Medical Journal Open, 8(3), e019228. https://doi.org/10.1136/bmjopen-2017-019228

Colley, D. G., Bustinduy, A. L., Secor, W. E., \& King, C. H. (2014). Human schistosomiasis. Lancet, 383(9936), 2253-2264. https://doi.org/10.1016/S01406736(13)61949-2

Coulibaly, J. T., N'Goran, E. K., Utzinger, J., Doenhoff, M. J., \& Dawson, E. M. (2013). A new rapid diagnostic test for detection of anti-Schistosoma mansoni and anti-Schistosoma haematobium antibodies. Parasites \& Vectors, 6(1), 29. https://doi.org/10.1186/1756-3305-6-29

Diagnositics, L. (2020). The Schistosoma ICT IgG-IgM test.

El-Ridi, R. (2013). Parasitic diseases: Schistosomiasis. BoD-Books on Demand.

Enk, M. J., e Silva, G. O., \& Rodrigues, N. B. (2012). Diagnostic accuracy and applicability of a PCR system for the detection of Schistosoma mansoni DNA in human urine samples from an endemic area. PLOS ONE, 7(6), e38947. https://doi.org/10.1371/journal.pone.0038947

Esrey, S. A., Potash, J. B., Roberts, L., \& Shiff, C. (1991). Effects of improved water supply and sanitation on ascariasis, diarrhoea, dracunculiasis, hookworm infection, schistosomiasis, and trachoma. Bulletin of the World Health Organization, 69(5), 609-621.

Gentile, R., Gonçalves, M. M. L., da CostaNeto, S. F., da Costa, M. M., Peralta, R. H. S., \& Peralta, J. M. (2011). Evaluation of immunological, parasitological and molecular methods for the diagnosis of Schistosoma mansoni infection before and after chemotherapy treatment with praziquantel in experimentally infected Nectomys squamipes. Veterinary Parasitology, 180(3-4), 243-249. https://doi.org/10.1016/j.vetpar.2011.03.007

Grimes, J. E., Croll, D., Harrison, W. E., Utzinger, J., Freeman, M. C., \& Templeton, M. R. (2015). The roles of water, sanitation and hygiene in reducing schistosomiasis: A review. Parasites \& Vectors, 8(1), 156. https://doi.org/10.1186/ S13071-015-0766-9

Halwindi, H., Magnussen, P., Olsen, A., \& Lisulo, M. (2017). Potential contribution of adult populations to the maintenance of schistosomiasis and soiltransmitted helminth infections in the siavonga and mazabuka districts of Zambia. Journal of Biosocial Science, 49(2), 265-275. https://doi.org/10. 1017/S0021932016000201

Houmsou, R. S., Wama, B. E., Agere, H., Uniga, J. A., Jerry, T. J., Azuaga, P., Amuta, E. U., \& Kela, S. L. (2021). Diagnostic accuracy of Schistosoma ICT IgG-IgM and comparison to other used techniques screening urinary schistosomiasis in Nigeria. Advances in Laboratory Medicine/avances En Medicina De Laboratorio, 2(1), 71-77. https://doi.org/10.1515/almed-2020-0093

Ibironke, O. A., Phillips, A. E., Garba, A., Lamine, S. M., \& Shiff, C. (2011). Diagnosis of Schistosoma haematobium by detection of specific DNA fragments from filtered urine samples. The American Journal of Tropical Medicine and Hygiene, 84(6), 998-1001. https://doi.org/10.4269/ajtmh.2011.10-0691

Kalinda, C., Chimbari, M. J., \& Mukaratirwa, S. (2018). Schistosomiasis in Zambia: A systematic review of past and present experiences. Infectious Diseases of Poverty, 7, 41. https://doi.org/10.1186/s40249-018-0424-5

Katz, N., Chaves, A., \& Pellegrino, J. (1972). A simple device for quantitative stoo thick-smear technique in Schistosomiasis mansoni. Revista Do Instituto De Medicina Tropical De São Paulo, 14(6), 397-400.

Knopp, S., Mgeni, A. F., Simba Khamis, I., Peter Steinmann, J., Stothard, R., Rollinson, D., Marti, H., \& Utzinger, J. (2008). Diagnosis of soil-transmitted helminths in the era of preventive chemotherapy: Effect of multiple stool sampling and use of different diagnostic techniques. PLoS Neglected Tropical Diseases, 2(11), e331. https://doi.org/10.1371/journal.pntd.0000331

LDBIO. (2017). Lateral flow tests - ICT: Point-of-care testing for parasites serology. L. Diagnostics. [Online]. Available: http://www.ldbiodiagnostics.com/m15-products.html.

Lodh, N., Mwansa, J. C. L., Mutengo, M. M., \& Shiff, C. J. (2013). Diagnosis of Schistosoma mansoni without the stool: Comparison of three diagnostic tests to detect Schiostosoma mansoni infection from filtered urine in
Zambia. The American Journal of Tropical Medicine and Hygiene, 89(1), 46. https://doi.org/10.4269/ajtmh.13-0104

MOH. (2017). Zambia national health strategic plan 2017-2021.

Montresor, A., Crompton, D. W. T., Hall, A., Bundy, D. A. P., Savioli, L., \& World Health Organization. (1998). Guidelines for the evaluation of soil-transmitted helminthiasis and schistosomiasis at community level: a guide for managers of control programmes (No. WHO/CTD/SIP/98.1). World Health Organization [Online]. Available: https://apps.who.int/iris/handle/10665/63821. Accessed: 08 December 2021.

Mott, K. E., Baltes, R., Bambagha, J., \& Baldassini, B. (1982). Field studies of a reusable polyamide filter for detection of Schistosoma haematobium eggs by urine filtration. Tropenmedizin Und Parasitologie, 33(4), 227-228.

Mutengo, M. M., Mwansa, J. C. L., Mduluza, T., Sianongo, S., \& Chipeta, J. (2014). High Schistosoma mansoni disease burden in a rural district of western Zambia. The American Journal of Tropical Medicine and Hygiene, 91(5), 965-972. https://doi.org/10.4269/ajtmh.13-0612

Rifai, N., Horvath, A. R., \& Wittwer, C. T. (2018). Tietz textbook of clinical chemistry and molecular diagnostics (6th ed.). Elsevier.

Ross, A. G. P., Chau, T. N., Inobaya, M. T., Olveda, R. M., Li, Y., \& Harn, D. A. (2017). A new global strategy for the elimination of schistosomiasis. International Journal of Infectious Diseases, 54, 130-137. https://doi.org/10.1016/j.ijid. 2016.09.023

Shehata, M. A., Chama, M. F., \& Funjika, E. (2018). Prevalence and intensity of Schistosoma haematobium infection among schoolchildren in central Zambia before and after mass treatment with a single dose of praziquantel. Tropical Parasitology, 8(1), 12-17. https://doi.org/10.4103/tp.TP_32_17

WHO. (2018). Zambia factsheet of health statistics. [Online]. Available: http:// www.aho.afro.who.int/profiles_information/images/7/70/Zambia-Stati stical_Factsheet.pdf.

\section{Publisher's Note}

Springer Nature remains neutral with regard to jurisdictional claims in published maps and institutional affiliations.

\section{Submit your manuscript to a SpringerOpen ${ }^{\circ}$ journal and benefit from:}

- Convenient online submission

- Rigorous peer review

- Open access: articles freely available online

- High visibility within the field

- Retaining the copyright to your article

Submit your next manuscript at $\boldsymbol{\nabla}$ springeropen.com 